\title{
IMMUNE RESPONSE TO POLYGLYCOLIC ACID IMPLANTS
}

\author{
SEPPO SANTAVIRTA, YRJÖ T. KONTTINEN, TOMOYUKI SAITO, MATS GRÖNBLAD, \\ ESA PARTIO, PERTTI KEMPPINEN, PENTTI ROKKANEN
}

From the University Central Hospital, Helsinki

\begin{abstract}
Cytological analysis of material aspirated from the effusion which occasionally develops around a polyglycolic acid (PGA) osteosynthesis implant showed a predominance of inflammatory monocytes and in particular lymphocytes. In order to discover whether PGA implants are immunologically inert, density gradient-isolated peripheral blood mononuclear cells were cultured in $0.2 \mathrm{ml}$ of $10 \% \triangle F C S-R P M I 1640$ culture medium supplemented with $10 \mathrm{mg}$ PGA. Phytohaemagglutin (PHA) lectin, a purified protein derivate of tuberculin (PPD) antigen and culture medium alone were used as positive and negative controls. We studied lymphocyte activation kinetics on days $0,1,3$ and 5. Major histocompatibility complex locus II antigen (MHC locus II antigen) and interleukin-2 receptor (IL-2R) expression were analysed using the avidin-biotin-peroxidase complex (ABC) method and lymphocyte DNA synthesis by using 3H-thymidine incorporation and beta-scintillation counting.

Especially on culture days 0 and 1 , lymphocytes and monocytes were seen by light microscopy to be attached to PGA particles. However, our results show no PGA-induced lymphocyte DNA synthesis, but PGA-induced MHC locus II antigen and IL-2R activation marker expression was seen, greater than in negative controls, but less than that seen in PPD antigen driven lymphocyte response. This suggests that PGA is an immunologically inert implant material, but it does seem to induce inflammatory mononuclear cell migration and adhesion, leading to a slight non-specific lymphocyte activation. This activation is lower than that seen in mitogen and antigen-driven lymphocyte responses.
\end{abstract}

Biodegradable polyglycolic acid (PGA) osteosynthesis implants have been successfully used for the fixation of cancellous bone fractures since 1984. Their major advantage is that they do not have to be removed. Their use in malleolar fractures (Rokkanen et al 1985; Böstman et al 1987) and in transepiphyseal fractures in children (Böstman et al 1989) has been reported and they are becoming more widely accepted.

Williams (1982) found that the hydrolysis of PGA takes place by essentially the same mechanism in vivo

S. Santavirta, MD, Consultant Orthopaedic Surgeon

E. Partio, MD, Research Fellow

P. Rokkanen, MD, Professor and Head of the Department of Orthopaedics and Traumatology

Helsinki University Central Hospital, Topeliksenkatu 5, SF-00260

Helsinki, Finland.

Y. T. Konttinen, MD, Senior Investigator

T. Saito, MD, Research Fellow

M. Grönblad, MD, Research Fellow

P. Kemppinen, MD, Research Fellow

Division of Rheumatology, Fourth Department of Medicine, Helsinki University Central Hospital, Unioninkatu 38, SF-00170, Helsinki, Finland.

Correspondence should be sent to Dr S. Santavirta at W. Aaltosentie 9, SF-00570 Helsinki, Finland.

(C) 1990 British Editorial Society of Bone and Joint Surgery

$0301-620 \mathrm{X} / 90 / 4115 \$ 2.00$

J Bone Joint Surg [Br] 1990; 72-B : 597-600. and in vitro, that is by hydrolysis in an aqueous environment. However, the process was greatly enhanced in vivo, probably by cellular response around the implant. In experimental animals, Vainionpää (1987) has shown that during fracture healing very little granulation tissue forms around PGA implants which are well tolerated by the surrounding tissue. However, in several hundred patients who have been treated with PGA implant osteosynthesis, mostly for malleolar fractures, noninfectious transient effusions have occurred in close to $5 \%$.

The present work was undertaken to analyse the human immunobiological response to PGA.

\section{MATERIALS AND METHODS}

Local reaction in patients. In two patients, four months after osteosynthesis of medial malleolar fractures with PGA Biofix implants, the fluid from around the implants was aspirated and submitted to cytological evaluation. The aspirate, which contained degraded PCA and cells, was pressed through a nylon filter. The cells so collected were washed in RPMI-1640 medium and then processed in a cytocentrifuge onto a glass objective and stained with haematoxylin.

Human lymphocyte cultures. Venous blood was obtained 
from five healthy volunteers in syringes containing preservative-free heparin. After an RPMI-1640 dilution (1:1) a lymphoprep (specific gravity $1.078 \mathrm{~g} / \mathrm{ml}$, Nyegaard, Norway) density gradient isolation of peripheral blood mononuclear cells was performed $(400 \mathrm{G}, 40 \mathrm{~min}$, $+22^{\circ} \mathrm{C}$ ). Then $2 \times 10^{5}$ isolated and washed cells were placed in $0.2 \mathrm{ml}$ (Falcon 3072, Becton Dickinson) or $2 \mathrm{ml}$ (Nuclon Delta SI, Denmark) flat-bottomed cell culture wells. In a preliminary study $10,100,1000$ and $10000 \mu \mathrm{g}$ quantities of fine pulverised PGA were tested. We used $10 \mathrm{mg}$ per well in subsequent experiments, because PGA had no toxic effect and $10 \mathrm{mg}$ could be easily visualised in the cytocentrifuged specimens.

Each analysis was performed in an identical manner with pigmented or unpigmented PGA (US Patent Office 1969). As negative controls we used plain $10 \% \Delta \mathrm{FCS}-$ RPMI-1640 media without PGA and as positive controls either phytohaemagglutinin (PHA, $1.25 \mu \mathrm{g}$ per well; Wellcome Diagnostics) or purified protein derivate of tuberculin (PPD, $10 \mu$ g per well; Statens Serum Institute, Denmark). The lymphocyte culture was kept in a $5 \%$
$\mathrm{CO}_{2}$-air mixture at $+37^{\circ} \mathrm{C}$. End-point analysis was performed at $0,1,3$ and 5 days to analyse the activation kinetics (Konttinen, Bluestein and Zvaifler 1985).

${ }^{3} \mathrm{H}$-thymidine incorporation. One $\mu \mathrm{Ci}\left(6-{ }^{3} \mathrm{H}\right)$ thymidine (specific activity $5 \mathrm{Ci} / \mathrm{mmol}$, Amersham, UK) was added to each well 18 to 24 hours before the cultures were harvested with a semi-automatic multi-sample harvester (MHCl, Skatron, Norway) on glass-fibre filters in triplicate. The filters were suspended in a scintillation solution before beta-scintillation counting in CKB Wallac 81000 counter (Wallac, Finland).

ABC staining. Avidin-biotin-peroxidase complex (ABC) (Hsu, Raine and Fanger 1981) staining consisted of the following steps:

1) fixation of the samples $\left(5 \mathrm{~min}\right.$ in acetone at $\left.4^{\circ} \mathrm{C}\right)$

2) inhibition of endogenic peroxidase $(5 \mathrm{~min}$ in $0.3 \%$ $\mathrm{H}_{2} \mathrm{O}_{2}$ )

3) blocking of non-specific binding sites $(20 \mathrm{~min}$ in $1: 5$ diluted normal horse serum)

4) incubation with monoclonal antibodies (30 min $\mathrm{MoAb}$ anti-CD2 $=\mathrm{T}$ lymphocyte marker, anti-C3bi $=$ mono-

Table I. Lymphocyte activation in peripheral blood mononuclear cell cultures exposed to nonpigmented and pigmented polyglycolic acid (PGA) compared to negative (culture medium alone) and positive (purified derivative of tuberculin: PPD) controls (mean + s.e.m.)

\begin{tabular}{|c|c|c|c|c|c|c|c|c|}
\hline & \multicolumn{4}{|c|}{ IL-2R } & \multicolumn{4}{|c|}{ MHC locus II Ag } \\
\hline & do & d1 & d3 & d5 & do & d1 & d3 & d5 \\
\hline $\begin{array}{l}\text { Culture } \\
\text { medium }\end{array}$ & 0 & 0 & 0 & $0.9+0.5$ & 0 & 0 & 0 & $0.4+0.4$ \\
\hline $\begin{array}{l}\text { PGA non- } \\
\text { pigmented }\end{array}$ & 0 & $1.5+0.9$ & $3.0+0.6$ & $4.8+0.3$ & 0 & $1.0+0.7$ & $2.8+1.1$ & $4.8+0.3$ \\
\hline $\begin{array}{l}\text { PGA } \\
\text { pigmented }\end{array}$ & 0 & $2.8+1.3$ & $3.8+0.8$ & $4.8+0.3$ & 0 & $1.3+0.9$ & $2.5+1.2$ & $5.0+0.4$ \\
\hline PPD & 0 & $2.8+0.3$ & $3.1+0.6$ & $8.9+2.4$ & 0 & $1.5+0.9$ & $3.0+0.6$ & $9.0+2.4$ \\
\hline
\end{tabular}

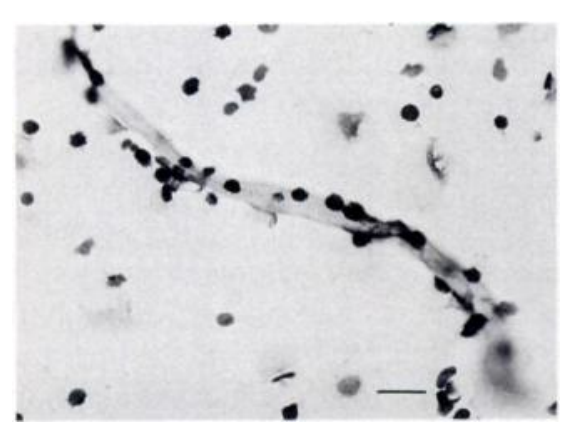

Fig. 1



Fig. 2

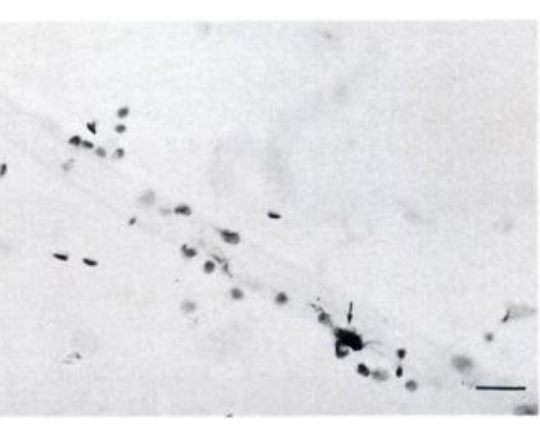

Fig. 3

Figure 1 - One-day (d1) mononuclear cell culture exposed to pigmented fibre of polyglycolic acid (PGA). CD2 positive T-lymphocytes staining with monoclonal T11 antibody adhere to PGA fibre. Figure 2 - One-day (d1) mononuclear cell culture exposed to non-pigmented PGA. Immunopositive C3bi positive monocytes (arrow) cling to the fibre. Note also adjacent unstained lymphocytes (arrow-heads). Figure 3 - Five-day (d5) mononuclear cell culture exposed to non-pigmented PGA. Activated cell (arrow) clinging to the fibre, most cells being resting lymphocytes. Haematoxylin counterstaining. $\mathrm{Bar}=20 \mu \mathrm{m}$. 
cyte marker, anti-IL-2R $=$ interleukin- 2 receptor or activated $\mathrm{T}$ cell marker, anti-MHC locus II antigen or activated $T$ cell marker)

5) incubation with biotinylated horse anti-mouse antibodies ( $30 \mathrm{~min}$ )

6) incubation with ABC complex (30 min)

7) development of colour reaction (3,3'-diaminobenzidine $50 \mathrm{mg} / 150 \mathrm{ml} \mathrm{PBS}$ in $0.003 \% \mathrm{H}_{2} \mathrm{O}_{2}$ )

8) counterstaining with haematoxylin

9) dehydration, clearing and mounting.

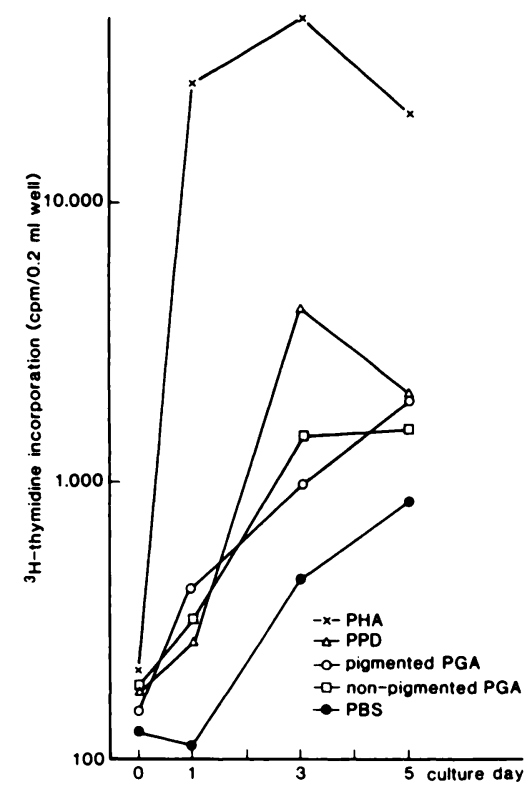

Fig. 4

\begin{abstract}
${ }^{3} \mathrm{H}$-thymidine incorporation in peripheral blood mononuclear cell cultures. Phytohaemagglutinin mitogen (PHA) and purified protein derivative of tuberculin antigen (PPD) were used as positive controls, and culture medium without additives (PBS) as a negative control. Polyglycolic acid (PGA), pigmented or non-pigmented, caused no measurable lymphocyte DNA synthesis in vitro.
\end{abstract}

Between each step, the cytospin specimens were washed twice for $5 \mathrm{~min}$ in PBS (0.1 mol$/ 1, \mathrm{pH} 7.4)$. The methods and analysis of results have been reported in more detail elsewhere (Konttinen et al 1988).

\section{RESULTS}

The main cell type found in the effusion samples around PGA implants in malleolar fractures was a small lymphocyte, though some monocytes were also seen.

In the in vitro study, $\mathrm{CD} 2$ positive lymphocytes (Fig. 1) as well as some C3bi positive monocytes (Fig. 2) were seen attached to $P G A$ particles in vitro, in particular during the culture days 0 and 1 . Subsequently, some activated lymphocytes (Fig. 3) were seen on culture days 3 and 5 in PGA-containing cultures.

PGA did not cause an increase in lymphocyte DNA synthesis as assessed by the ${ }^{3} \mathrm{H}$-thymidine incorporation method (Fig. 4). The lymphocyte proliferation caused by PHA showed that the indicator cells had a full action capacity (Fig. 4).

The more sensitive analysis of lymphocyte activation markers showed that PGA induced an expression of IL2R antigen (Table I) as well as of $\mathrm{MHC}$ locus II antigen (Table I). This differed clearly from the background reaction caused by the cell culture medium, but was lower than the antigen stimulus caused by PPD. The results with pigmented and unpigmented PGA were similar.

\section{DISCUSSION}

The disadvantage of conventional metal fracture fixation implants have encouraged the search for an absorbable device. Such a material must fulfil several basic demands, one of them being good compatibility between tissue and implant. Clinically PGA implants have proved to be particularly suitable for the fixation of cancellous bone fractures (Rokkanen et al 1985; Böstman et al 1987), and these implants can be used for transepiphyseal fracture fixation in children without impairment of the physeal function (Böstman et al 1989; Mäkelä 1989).

Recent research has shown that there are often unpredictable adverse reactions to some commonly used traditional implant materials (Santavirta et al 1989; Tallroth et al 1989). Probably all osteosynthesis materials and particularly all new developments should undergo investigation of their immunobiological response.

In the present study, the cell type analysis of the clinical effusion samples indicated lymphocytes as the main cell type, though some monocytes were also found. The absence of neutrophils is evidence for the sterile, non-infectious nature of the tissue response. Interestingly, mononuclear phagocytes were not the dominant cell population which makes us suspect that there was a lymphocyte-mediated immunological reaction against the implant.

In human lymphocyte cultures, the ${ }^{3} \mathrm{H}$-thymidine incorporation method appears to be not sensitive enough to detect the lymphocyte activation. With the more sensitive activation marker method, PGA caused interleukin-2 receptor and $\mathrm{MHC}$ locus II antigen expression, this reaction being, however, more modest than the one caused by antigen PPD. The fact that PGA appears to be immunologically relatively inert, even as compared with antigenic PPD, fits with the good clinical experience.

No benefits in any form have been received or will be received from a commercial party related directly or indirectly to the subject of this article. 


\section{REFERENCES}

Böstman O, Vainionpää S, Hirvensalo E, et al. Biodegradable internal fixation for malleolar fractures: a prospective randomised trial. $J$ Bone Joint Surg [Br] 1987; 69-B:615-9.

Böstman O, Mäkelä EA, Törmälä P, Rokkanen P. Transphyseal fracture fixation using biodegradable pins. J Bone Joint Surg [Br] 1989; 71B:706.

Hsu SM, Raine L, Fanger H. Use of avidin-biotin-peroxidase complex (ABC) in immunoperoxidase techniques. J Histochem Cytochem $1981 ; 29: 577-80$.

Konttinen YT, Bluestein HG, Zvaifler NJ. Regulation of the growth of Epstein-Barr virus-infected B cells. I. Growth regression by Erosetting cells from VCA-positive donors is a combined effect of autologous mixed leukocyte reaction and activation of $\mathrm{T}^{+}$memory cells. J Immunol 1985; $134: 2287-93$.

Konttinen YT, Segerberg-Konttinen M, Nordström D, et al. An immunoperoxidase-autoradiography double labeling method for analysis of lymphocyte activation markers and DNA synthesis. $J$ Immunol Methods 1988; 110:19-27.
Mäkelä EA. Fixation properties and biodegradation of absorbable implants in growing bone. Thesis, Helsinki 1989.

Rokkanen P, Böstman O, Vainionpää S, et al. Biodegradable implants in fracture fixation: early results of treatment of fractures of the ankle. Lancet 1985 ; i:1422-4.

Santavirta S, Konttinen YT, Nordström D, et al. Immune-inflammatory response in infected arthroplasties. Acta Orthop Scand 1989; 60:116-8.

Tallroth K, Eskola A, Santavirta S, Konttinen YT, Lindholm TS. Aggressive granulomatous lesions after hip arthroplasty. $J$ Bone Joint Surg [Br] 1989; 71-B:571-5.

US Patent Office. Inventors: Schmitt EE, Polostina RA. Polyglycolic acid prosthetic devices. US Patent, 3463158, 1969.

Vainionpää S. Biodegradation and fixation properties of biodegradable implants in bone tissue. Thesis, Helsinki 1987.

Williams DF. Biodegradation of surgical polymers. J Mat Sci 1982; $17: 1233-46$ 